\title{
Decriminalizing drug addiction: the effects of the label
}

\begin{abstract}
The mass incarceration epidemic related to drug offenses in the United States has caused recent introspection regarding the best technique to employ when future deterrence is the end goal. The focus of this present work centers on the opioid crisis in America and comparable westernized countries worldwide. Emphasis has been placed on a harm reduction approach. This innovative policy is a natural extension of combating the negative impact and damaging result of labeling. When one is allowed to avoid the badge of "criminal," they can conceivably concentrate on getting clean and staying that way. This includes access to legitimate jobs and ongoing positive role models. A productive, upstanding future life is the ultimate aim.
\end{abstract}

Volume 7 Issue 4 - 2019

\author{
Morgan Joyce, Emmalie Sklenar, Georgie Ann \\ Weatherby \\ Department of Sociology \& Criminology, Gonzaga University, \\ USA
}

Correspondence: Georgie Ann Weatherby, Department of Sociology \& Criminology, Gonzaga University, USA, Email weatherb@gonzaga.edu

Received: June 13, 2019 | Published: July 09, 2019

\section{Introduction}

No issue has had more impact on the criminal justice system in the past three decades than national drug policy. The "war on drugs," officially declared in the early 1980s, has been a primary contributor to the enormous growth of the prison system in the United States during the last quarter-century and has affected all aspects of the criminal justice system and, consequently, American society. As a response to the problem of drug abuse, national drug policies have emphasized punishment over treatment, and in a manner that has had a disproportionate impact on low-income, minority communities, especially with mandatory minimum sentencing. After millions of people have been arrested and incarcerated, it is clear that the "war on drugs" has reshaped the way America responds to crime and ushered in an era of instability and mistrust in countless communities. Finding alternatives to prison for drug addicts is an extremely important step in substance abuse recovery. There is an "idea that perhaps other avenues of dealing with the current drug problem, especially in the USA, should be explored, especially considering the fact that the current "get tough" policies on illicit drugs have cost billions of dollars, while failing to curtail illicit drug supplies and, at the same time, expanding current USA prison populations". ${ }^{1}$ Substance abuse is a serious disease and therefore should not be treated as a crime, but rather examined as a social problem as well as a health problem that needs to be addressed in alternate ways.

Effectively managing drug-involved offenders is an essential step to reduce crime and drug abuse. Statistics from the Bureau of Prisons (BOP) show that $46 \%$ of America's prison population is occupied by drug offenses. ${ }^{2}$ In addition, surveys conducted by the National Institute of Health and the United States Department of Justice (DOJ) indicate that nearly 70 percent of prisoners in state or local prisons and 65 percent of prisoners in federal prisons regularly engaged in some type of drug use prior to being incarcerated. The United States Department of Health and Human Services, HHS, developed a fivepoint plan to combat the nationwide opioid epidemic. It included things such as better addiction prevention, treatment, and recovery services, better data, and better research. While this plan was designed to combat opioid misuse, the general themes can be applied to tackling drug misuse of any kind. Sutherland et al., ${ }^{3}$ differential association theory and Becker's ${ }^{4}$ labeling theory will be used to assess current policies as well as to provide solutions that may be used in the future for drug abuse. By helping those addicted to drugs through diversion and arrest-referral programs instead of incarcerating them, the cycle of recidivism will lower.

\section{Review of the literature}

\section{History}

During the Civil War, opioid drugs, specifically morphine, were dispensed freely for all kinds of medical ailments and were widely used as a painkiller. As a result, an estimated 400,000 soldiers became addicted. ${ }^{5}$ By the second half of the nineteenth century, scientists had begun to look for a less addictive form of morphine, and in 1874, an English chemist named Alder Wright first refined heroin from a morphine base. ${ }^{5}$ The drug was intended to be a safer replacement for morphine. Heroin was used in medicine until its addictive properties became known. In the 1890s, a German pharmaceutical company, Bayer, marketed heroin as morphine substitutes and cough suppressant. Bayer promoted heroin for use in children suffering from coughs and colds. ${ }^{5}$ Partly as a result of these medical treatments, by the early 1900s, heroin addiction in the United States had skyrocketed. The current wave of the prescription opioid epidemic can be traced back to 1995, when the Food and Drug Administration approved Oxycodone, which was sold under the name of OxyContin. The pharmaceutical company, Purdue Pharma, then targeted specific physicians with their marketing of the opioid. Purdue Pharma would target busy primary-care physicians, doctors who already prescribed a higher number of opioids, and doctors who saw patients with chronic pain. Purdue Pharma funded clinical trials that showed OxyContin's long lasting pain relief with few side effects compared to other opioids. ${ }^{6}$ The Company's marketing campaign was successful. The sales of Oxycodone grew from \$48 million in 1996 to $\$ 1.1$ billion in $2000 .^{7}$ By 2007, Purdue Pharma pleaded guilty to intentionally lying about the addictive risks of using OxyContin. The pharmaceutical company paid $\$ 634$ million in fines. ${ }^{7}$ The United States is currently experiencing opioid misuse at an epidemic level. Opioids are pain killers that interact with the brain and body's opioid receptors. ${ }^{8}$

The opioid epidemic is fueled by both prescription opioids that have been approved by the FDA and promoted by pharmaceutical companies as well as imported drugs like heroin and the synthetic opioid, fentanyl. Since the mid-1990s, black tar heroin has been the main type of heroin available, which is different than the traditional 
white powder form in terms of its purity, price, and how it is ingested. In today's society, black tar heroin tends to be more popular than traditional white powder heroin because it is cheaper in price and more easily available on the streets. The opioid epidemic is prevalent in all 50 states, in both rural and urban areas; but, compared to other drug epidemics that the nation has experienced, the face of the opioid epidemic has been overwhelmingly white. As a result of the demographic of users and abusers being white, the response to handling the epidemic has been significantly different than if the users were people of color. In the 1980s-1990s, the nation experienced a crack cocaine scare where the face of this epidemic was a majority black. The nation looked to a war on drugs and a crackdown on crime. ${ }^{9}$ Now, with the opioid epidemic being disproportionately white, the nation cannot arrest their way out of the problem. Instead, policies have to be implemented to stop more people from being addicted. While the epidemic is affecting people of all races and from all areas, white communities are suffering the most from the epidemic.

Recently, there has been a significant increase in drug overdoses for young white males, often in rural areas. A theory for why white communities are the ones most significantly impacted is because doctors are unconsciously cautious and hesitant when prescribing medication to their non-white patients. As a result, white patients are more likely to walk away with an opioid prescription from their doctor compared to patients of Black or Latino ethnicities. ${ }^{9}$ This is where the natural history of opioid abuse as well as overall drug use comes from, but it wasn't until the late $19^{\text {th }}$ century that the United States began regulating the use and distribution of narcotics and other consciousness-altering drugs. Both State and Federal legislation have focused equally on the use and distribution of drugs. Therefore, the criminal justice system is now at the center of drug-control efforts.

\section{Labeling theory}

Labeling theory states that people come to identify and behave in ways that reflect how others label them. Howard Becker, ${ }^{4}$ the sociologist behind labeling theory, provides an explanation for how and why deviance occurs. "Deviance is not a quality of the act the person commits, but rather a consequence of the application by others of rules and sanctions to an 'offender.' The deviant is one to whom that label has successfully been applied; deviant behavior is behavior that people so label". ${ }^{4}$ Labeling and treating someone as criminally deviant can actually foster deviant behavior. Labeling someone as criminal, for example, can cause others to treat them more negatively and the response to being treated more negatively can be in turn for that person to act more negatively. "It begins with the assumption that no act is intrinsically criminal. Definitions of criminality are established by those in power through the formulation of laws and the interpretation of those laws by police, courts, and correctional institutions". ${ }^{10}$ Once a person is labeled as deviant, it is extremely difficult to remove that label. The deviant person becomes stigmatized as a criminal or deviant and is likely to be considered, and treated, as untrustworthy by others. The deviant individual is then likely to accept the label that has been attached, seeing himself or herself as deviant, and act in a way that fulfills the expectations of that label. Labeling significantly impacts the lives of all types of drug users and abusers, but opioid abusers are especially impacted. Labeling can negatively impact a user's willingness to attend treatment or gain access to healthcare, harm reduction, self-esteem, and mental health. ${ }^{11}$

In general, society holds a negative opinion about drug users and their addiction. However, prescription drugs avoid this stigmatization since there is a sense of trust associated with health care professionals. Recovery Brands, a team working on elevating the standards of addiction treatment in the United States through connecting those who need treatment and those who can help, conducted a survey of people who use drugs and what they wished people would understand about addiction. The responses showed the dominating power of addiction in relation to value as a person. "Just because I am/was an addict, doesn't make me a bad person. Deep down inside we are wonderful, loving people". ${ }^{11}$ This shows that addicts themselves feel the stigma from using. Drug users who experience stigma in relation to their drug use are less likely to seek treatment for their addiction. The stigma toward addicts is also prevalent in the medical field. Studies have found that workers in the medical field hold negative views of patients who are drug dependent. "When health providers carry a stigma toward people with drug dependencies, it can affect their willingness to assess or treat the patient for substance abuse, how they approach him or her, and it may prevent addicted individuals from seeking healthcare altogether". ${ }^{11}$ Labeling also impacts the public perception of harm reduction strategies. The defining features of harm reduction "are the focus on the prevention of harm, rather than on the prevention of drug use itself, and the focus on people who continue to use drugs". ${ }^{12}$ Stigma impacts harm reduction strategies through the public perception of their interventions, including needle exchanges and safe drug consumption rooms. The stigma can even lead to the public thinking harm reduction strategies "facilitate and encourage drug use". ${ }^{11}$

Lastly, perceived stigma can significantly impact the social lives and mental health of drug users. Drug users can feel pushed out of society, or alienated from their community. This results in the drug users being isolated and lonely. The lack of community ties or support systems then impacts their likeliness to seek treatment or help. The label that is associated with using drugs can be internalized and severely impact the user's mental health. They can recognize themselves as being deviant, which not only can negatively impact their self-esteem, but enable them to envision themselves as deviant because of their drug use, which can lead to them becoming deviant in other areas of their life. ${ }^{11}$ The effects of labeling theory are most prevalent when addicts try to break through their addiction because they are labeled by the rest of society. Addicts face both formal and informal labeling. Formal labeling is carried out by professionals like social workers, whereas informal labeling is done by nonprofessionals like family and friends. ${ }^{13}$ Different theoretical approaches have been adapted into treatment policies to combat the opioid epidemic. Diversion programs, especially involving juveniles, were designed as an application of labeling theory.

Formally being labeled deviant after their initial drug use as a juvenile predicted greater follow-up drug use. ${ }^{13}$ Through these diversion programs, users are less exposed to stigmatizing social services. By reducing interaction with stigmatizing social services, a user does not receive the label of a drug user and deviant. Thus, these users avoid internalizing the label and the ensuing cycle of using drugs that being labeled increases their chances of. In regard to drug addiction, these individuals are labeled as drug addicts or junkies and those that commit drug-related crimes are usually labeled as both addicts and criminals. What society thinks happens to these individuals is that they get caught, arrested, sent to prison for a few years, and then come out and go on with their lives, but that is far from the truth. Once a person is labeled as a criminal or an addict, their lives are changed forever. Society places these labels on them and 
they have a hard time disassociating themselves from those labels. Soon enough, they will conform to those labels, which are seen with the high rates of recidivism.

\section{Differential association theory}

Differential association theory is based upon the idea that criminals commit crimes as a result of their association with other people. In other words, "a person becomes delinquent because of an excess of definitions favorable to violation of law over definitions unfavorable to violation of law". ${ }^{3}$ Learning about crime includes learning the techniques of committing a crime, as well as learning the motivation and attitudes toward crime. This theory can be applied to drug addiction as well as committing drug-related crimes because people learn that behavior from those that they hang around. For example, high school and even college students may be attempting to make new friends and trying to fit in so they are willing to experiment with a drug and then they end up continuing the drug because the people that they associate themselves with do the drug as well. Another common example is if a parent or close relative uses drugs or commits a drug-related crime and an individual is around that influence all the time growing up, they may learn that behavior and the language that surrounds it and end up doing the same thing, therefore creating a potentially endless cycle.

Differential association theory can also work in a constructive way in regard to drug courts, treatment programs, and other positive support groups. For example, members in drug court help to support each other and hold each other accountable, creating positive relationships for the whole. In this way, individuals learn how to live a more positive lifestyle with the help of their fellow members in drug court. Drug courts also form a family connection with both the former drug users as well as the legal participants in the court. This community takes on a family dynamic where the judge is seen as a paternal/maternal figure. This may be offenders' first experience with a positive adult influence who takes genuine interest in helping to turn these individuals' lives around. As the theories suggest, if the U.S. is to successfully confront and ultimately reduce drug abuse, society must recognize the social circumstance(s) that the individual finds him/herself in, rather than to merely arrest, prosecute, and punish the individual in an unbreakable cycle.

\section{Methods and data}

\section{Preface}

The following section will provide data documenting substance abuse over the past 30 years and how these have changed, including the drug of choice in each given era. It will also include data on how many people are imprisoned because of substance abuse and what that looks like. Both statistical data as well as qualitative data will be presented. Data from The Sentencing Project and the Center for Disease Control (CDC), among others will be included.

\section{General overview}

The current research suggests that $\mathrm{H}_{1}=$ diversion programs lower overall recidivism rates. The null hypothesis is $\mathrm{H}_{0}=$ diversion programs have no impact on recidivism rates. Through secondary analysis of pre-existing data, drugs, especially opioids, will be highlighted with their relationship to the prison population. A qualitative study examining the transition from opioid pain pills to injecting heroin will be another point of datum that will be studied for the analysis. The face of addiction, the perception of those battling addiction and the treatment of drug addiction has changed a great deal throughout the years in the United States. The Substance Abuse and Mental Health Services Administration survey published that 24.6million Americans (over the age of 11) were considered current illicit drug abusers and had used an illicit drug in the month before the survey, and 21.6 million people were considered to have a substance abuse or dependency issue in the previous year. ${ }^{14}$ This demonstrates the vast number of people who have used or are currently using drugs and points out that this is a major social problem in the U.S. today. Associated with these patterns of abuse, in 2008, prisoners serving time under state jurisdictions for drug-related offenses comprised 18 percent of the prison population. In 2009, nearly half of federal prisoners were serving time for some type of drug-related criminal behavior. Even in this one-year difference between 2008 and 2009, there was roughly a $30 \%$ increase in the amount of prisoners in prison for drug-related crimes.

In 2012, 309, 100 prisoners were in prison for drug related crimes. ${ }^{15}$ According to the United States Department of Justice, nearly 5million were on parole or probation. ${ }^{16}$ In addition, surveys indicate that nearly 70 percent of prisoners in state or local prisons and 65 percent of prisoners in federal prisons regularly engaged in some type of drug use prior to being incarcerated. ${ }^{17}$ The same research indicates that nearly 25 percent of violent offenders in state prisons committed the act that led to incarceration under the influence of some drug. With the current opioid epidemic that the U.S. is facing, the number of Americans that abuse substances has increased dramatically, which in turn will lead to higher numbers of people in prison for drug-related crimes from 2015 to the present day. Due to the current policy of arresting and imprisoning substance abusers as well as sellers, more than $60 \%$ of all federal prisoners and $22 \%$ of all state prisoners are in prison for drug offenses. ${ }^{18}$ This is a lot to take in, but what does it really mean? The data show that in the U.S., there is a serious problem regarding substance abuse and that it is currently treated as a criminal justice problem, rather than a medical or social issue. Consequently, the solutions that are in place now come from within the criminal justice system. Although crime rates in general have declined over recent years, the arrest and incarceration rates have skyrocketed within the last 10 years.

\section{Drug abuse and people of color}

Datum on regular drug users, compiled by household surveys conducted by the Department of Health and Human Services, have consistently shown over many years that the number of drug users generally reflects disproportionately the racial/ethnic groups of the national population. That is, whites, blacks, and Latinos use drugs at relatively similar rates, but arrests vary significantly. Results from the ADAM (Arrestee Drug Abuse Monitoring) data set presented in the annual National Institute of Justice reports suggest that some drugs are more likely to be associated with specific ethnic groups. ${ }^{19}$ The heroin and cocaine study in 1997 showed the intersection of drugs and race and indicated that drug use among blacks is concentrated in crack, followed by heroin. Drug use among whites and Hispanics is fairly evenly distributed across cocaine and heroin. ${ }^{9}$ About threequarters of drug offenders in federal prison were either non-Hispanic black or African American (39\%) or Hispanic or Latino (37\%); nearly a quarter $(22 \%)$ were non-Hispanic white offenders in a 2012 study on drug offenders in federal prisons. ${ }^{20}$ 
Why is this the case? Studies have shown that different racial groups tend to use drugs at a relatively similar rate, but we see a disproportionate amount of people of color in prison for drug-related offenses. A prime example of this is the racial disparities between crack and powder cocaine sentencing. Prior to 2010, federal law recognized 100 grams of powder cocaine and one gram of crack as equivalents. Minimum sentencing for offenders in possession of five or less grams of crack received a five-year mandatory minimum prison sentence, while those in possession of 500 grams or less of cocaine received the same sentence. This disproportionately affected young, low-income, African American males who represented the majority of those prosecuted for crack possession, in comparison to cocaine offenders who were predominantly Caucasian. In the U.S. Federal Court of Appeals case, United States v. Blewett, of the 30,000 federal prisoners serving crack-cocaine sentences, more than $80 \%$ were black. ${ }^{21}$ The current 18:1 ratio, which is to say that 18 grams of powder cocaine will now render the same punishment as 1gram of crack cocaine, is better than the previous 100:1, but is still a large, concerning discrepancy.

\section{Opioids}

The first wave began with increased prescribing of opioids in the 1990 s, with overdose deaths involving prescription opioids (natural and semi-synthetic opioids and methadone) increasing since at least 1999. The second wave began in 2010, with rapid increases in overdose deaths involving heroin. The third wave began in 2013, with significant increases in overdose deaths involving synthetic opioids - particularly those involving illicitly-manufactured fentanyl (IMF). The IMF market continues to change, and IMF can be found in combination with heroin, counterfeit pills, and cocaine. ${ }^{22}$ The opioid epidemic of roughly the last five years has come about because of doctors across the U.S prescribing opioids in bulk to patients to help with their pain. The most common prescription opioids include drugs such as OxyContin, Percocet, Vicodin, and Fentanyl. Opioid overdoses accounted for more than 42,000 deaths in 2017, more than any previous year on record. ${ }^{23}$

Addiction to drugs, especially opioids in the recent years, can often result in individuals ending up incarcerated because they will go to extreme lengths in order to get their high, which often includes acts such as robbery or theft in order to gain money to buy their drug. Past misuse of prescription opioids is the strongest risk factor for starting heroin use, especially among people who became dependent upon or have abused prescription opioids in the past year. This indicates that widespread opioid exposure and increasing rates of opioid addiction have played a major role in the growth of heroin use. Among new heroin users during 2000 to 2013, approximately three out of four report having misused prescription opioids prior to using heroin. ${ }^{24}$ Heroin is typically used by individuals who were previously addicted to prescription opioids. Heroin is a lot cheaper, more readily available on the street, and stronger than prescription opioids, so when an individual believes the high off of prescription drugs isn't strong enough anymore, they turn to heroin.

\section{Every 'Never' I ever said came true}

The qualitative study "Every 'Never' I Ever Said Came True': Transitions from opioid pills to heroin injecting," studies the effects that age and location have on a users' transition from taking opioid pills to injecting heroin. The study was conducted by Sarah G Mars et al., ${ }^{25}$ in 2012, by interviewing "self-reported current heroin injectors living in either San Francisco or Philadelphia". ${ }^{25}$ This study gave strong insight into the process opioids users experience as they transition from taking opioid pills to injecting heroin. While there has been a lot of research into how and why the opioid epidemic started and how to stop it, there is very limited research to explain why users transition from their prescription opioid pills to other types of opioids, most commonly heroin. Many opioid users are forced to transition to heroin from prescription opioids because of the cost or limitation in prescriptions from their doctors. Heroin is significantly cheaper than prescription pills. However, because prescription pills are regulated by the FDA, the risk of having the opioid laced or not a true version of itself is gone. This study shows how users make that transition from different forms of opioids. While studying cities on the different ends of the nation, the results they found were that they had parallel characteristics for transitioning. Twenty-two current heroin users were interviewed in Philadelphia and nineteen were interviewed in San Francisco. The two cities were chosen for their "contrasting political economies, immigration patterns and source type of heroin". ${ }^{25}$ The drug scenes in the two cities were also contrasting.

In Philadelphia, the drug scene was visible and easily accessible. Heroin and syringes could be bought on street corners without need for any connections to current or previous users or dealers. Heroin could be inexpensively and easily obtained. San Francisco gentrification forced heroin users out into the nearby city of Oakland. Obtaining opioids in San Francisco required local knowledge as well as either a dealer who would deliver or a trip to Oakland. Researchers identified two types of opioid users based on their introduction to heroin use, pill initiates and heroin initiates. Pill initiates were users who transitioned to heroin from opioid pills. In comparison, heroin initiates went straight to heroin use. Both cities saw the same significant difference in the patterns heroin initiation by younger heroin injectors, 20-29years old, and older injectors, 30years and older. The younger injectors on average were pill initiates, while older injectors were heroin initiates. Younger injectors had transitioned to heroin through opioid pills initially prescribed for injury or pain. Older injectors transitioned to heroin through the use of other drugs like marijuana, cocaine, methamphetamine, etc. These drugs are considered "gate-way drugs," where the use of one drug leads to the use of other addictive drugs. While older drug users transitioned from using other drugs, only one of the respondents reported using opioid pills, showing that while they transitioned from other drugs, they didn't use opioid pills like that of younger users. Heroin initiates only reported the use of opioid pills after they began injecting heroin. Both cities also saw similar contrast in age and years of use between pill initiates and heroin initiates. "In Philadelphia, 14 of the 22 participants were pill initiates with a mean age of 31 and 7mean years' use. Among the eight heroin initiates, the mean age was 44 and their mean years' use was 23. In San Francisco, 11 of the 19heroin injectors were pill initiates, with a mean age of 29 and mean years' use of 5.8. The eight heroin initiates had a mean age of 50 years and their mean years' use was 20 ". ${ }^{25}$

Overall, pill initiates were younger than heroin initiates, with fewer years of drug use. An overall theme that addicts suffer from is maintaining a constant supply. In both cities, users had to transition to heroin due to the difficulty in obtaining pills. In both cities, opioid pills are significantly more expensive, and highly regulated. Some partake in the technique of "doctor shopping." Doctor shopping is defined as the "patient obtaining controlled substances from multiple healthcare practitioners without the prescribers' knowledge of the other prescriptions". ${ }^{26}$ Since opioids are highly regulated, this is 
one of many tactics users have to use to keep up their supply. When users face hardships with acquiring prescription drugs, they have to make the decision if they will transition to cheaper and more easily accessible heroin. One interviewee was initially prescribed Percocet for a knee injury, but eventually transitioned to using heroin due to difficulty obtaining prescription opioids.

"...I guess like a lot of people, you start on the pills, and then the doctor gives you some and some more [...] I took what he gave me, plus whatever - buying more on the street, and at some point in time, just the pills aren't doing it, and they're a little harder to find. [...] Every morning we would go to the one place and they had both things [heroin and pills] but [...] they never were out of heroin, but once in a while - well, three times a week probably, they didn't have the pills. So I'd have to scramble around, and then I finally had enough and said "Fuck. The hell with this, give me a bag [of heroin]!" and was off to the races". ${ }^{25}$ Researchers describe the process of "crossing the threshold" from using opioid pills to injecting heroin. The process follows a typical progression where the user starts with either chewing opioid pills or crushing them into a powder to sniff or smoke. This is followed by sniffing or smoking heroin, and eventually injecting heroin. This progression was attributed to both the users' increasing tolerance, and the financial benefits from switching from costly pills to inexpensive heroin.

In conclusion, the researchers found in both cities that there was a dramatic difference in how older and younger heroin injectors were initiated into their heroin use. Younger heroin injectors were pill initiates. Older heroin injectors typically were heroin initiates, but when they transitioned drug use, it involved drugs other than opioid pills. While other drugs had potential of being "gate-way" drugs, opioid pills had the strongest relationship with heroin. The qualitative study illustrates the different routes opioid users take that result in them injecting heroin. Even though the two cities studied had contrasting drug scene characteristics, the results appeared to parallel one another. Both San Francisco and Philadelphia had similar age and usage experience ranges for pill initiates in comparison to heroin initiates.

\section{Methamphetamine \& other drugs}

Available data on typical methamphetamine users reveal that most are white, are in their $20 \mathrm{~s}$ or $30 \mathrm{~s}$, have a high school education or better, and are employed full- or part-time. ${ }^{27}$ More than two-thirds (67 percent) of the meth users showed positive results for two or more drugs compared with only 26 percent of the other ADAM arrestees, suggesting that meth users are more likely to use multiple drugs. Most commonly, people who use meth also use heroin because studies show that combining meth with heroin produces a more potent effect than either drug alone, based on the dosages of each. ${ }^{28}$ As is drawn from the aforementioned data above, the demographics of a cocaine user are usually white, middle to upper class and usually between the ages of 18-25. Cocaine is prevalent among college students as well, but is seen less as a substance abuse $\mathrm{e}^{29}$ problem because of the demographic of its users. Because of this, less people are getting treatment for cocaine addiction as opposed to other drugs.

\section{Theories}

The qualitative study "Every 'Never' I Ever Said Came True': Transitions from opioid pills to heroin injecting". ${ }^{25}$ describes the impact of labeling drugs as deviant and stigmatizing them over other drugs. Prescription opioids have avoided the harsh label of deviance that has been strongly associated with heroin. As a result, users are less fearful and precautious with their use. Most individuals have heard horror stories about the addictiveness of heroin and the serious consequences of using the drug just one time. While prescription opioids have similar addictive qualities as heroin, this label of addiction and deviance isn't associated with both. Through labeling prescription opioids as just as dangerous as street opioids like heroin, the transition from prescription opioids to heroin becomes transparent. "Every 'Never' I Ever Said Came True': Transitions from opioid pills to heroin injecting", ${ }^{25}$ shows the power of differential association and how deviant peers can lead to personal deviance. "Several pill initiates described how friends they had known before their opiate use had guided them along the same path, using opioids first and then heroin, leading them to new sources and modes of administration as they followed in their wake". ${ }^{25}$ Through these relationships, non-users were taught how to access and use different types of drugs.

\section{Review of existing social policies and programs}

\section{Values}

All drug addiction should be viewed as a social and public health problem, just as are alcohol and tobacco addictions, to be addressed through preventive measures. Law enforcement cannot solve the national drug problem and a focus on law enforcement and corrections diverts attention and resources away from other needed approaches such as prevention, education, and treatment. "Since the 1950s, state institutions and American political culture have repeatedly constructed the war on drugs through the framework of suburban crisis and positioned white middle-class as innocent victims who must be shielded from both the illegal drug markets and the criminal drug laws. Scholars primarily have analyzed the U.S. drug war as a racial system of social control of urban minority populations, an extension of the punitive war on crime". ${ }^{30}$

\section{Failed policies}

The possession and sale of narcotics were criminalized in 1952 and 1956 with the passage of the Boggs Act and the Narcotic Control Act respectively, which came with high penalties for drug possession and the sale of narcotics. ${ }^{5}$ There has been a long list in history of how our society treats those that are addicted to drugs and criminalizes the acts that come along with being an addict such as use, possession, and sale of drugs. It is important to note that with the war on drugs and these acts being implemented, there were a lot of drug users who were being put into jail with this "tough on crime" policy. Under the Boggs Act, simple possession of cocaine, heroin or cannabis carried a mandatory minimum 2 years with a maximum 5 year prison term. A second offense carried a mandatory minimum 5 years with a maximum of 10 years in prison. A third offense carried a mandatory minimum of 10 years with a maximum of 15 years in prison.

The Narcotics Control Act of 1956 increased sentences for drug traffickers to a five-year mandatory minimum for a first offense and a 10-year mandatory minimum for all subsequent violations. The Act also forbade judges from suspending sentences or imposing probation in cases where they felt a prison sentence was inappropriate. Both the Boggs Act of 1951 and the Narcotics Control Act of 1956 failed miserably. The rationale for both bills and the mandatory minimum 
sentences had little or no impact on the spread of drugs throughout the country. To the contrary, the popularity of illegal drugs continued to grow. The Boggs and Narcotics Control Act essentially set the stage for mass incarceration. They wanted society to know that possession of drugs and intent to sell is a serious crime, but rather than helping them get treatment, they arrested these individuals.

\section{Drug courts \& diversion programs}

Since the inception of drug courts in 1989 , there has been a broad expansion of interest and programming in this area. Drug courts offer an alternative to individuals whose criminal behavior stems from drug use. In exchange for successfully completing treatment, the court may dismiss the original charge, reduce or set aside the sentence, or offer a lesser penalty. Drug courts vary significantly in many ways, including criteria for admission, type of treatment programming, and impact on sentencing. Drug courts are an attempt to rehabilitate substanceinvolved offenders while keeping them out of prison. The goals of drug courts are to reduce recidivism, reduce substance use, reduce the costs of drug-involved crimes, and decrease prison crowding. Based on several retrospective and quasi-experimental studies, it appears that drug courts are accomplishing most of their goals. Graduates have lower rates of recidivism and substance use, and the treatment is far more cost effective than incarceration. ${ }^{31}$

Differential association theory explains that through interaction with others, individuals learn the values, attitudes, techniques, and motives for criminal behavior and that the principal part of the learning of criminal behavior occurs within intimate personal groups. However, that being said, differential association theory can also be used in a positive and constructive way, as seen in drug courts. Drug courts build relationships between drug-users, past drug addicts, and legal professionals. Introducing these positive relationships into the lives of drug addicts, who have the majority of relationships with other drug users, allows for these addicts to build networks with individuals not predisposed to committing the same acts. These relationships prove important to keeping users accountable and sober. Instead of using their relationships to learn new deviant skills, these relationships formed through drug courts teach users positive life skills to which they may not otherwise be exposed. While differential association can prove harmful in the lives of drug addicts when they are surrounded by other drug users, when they are surrounded with positive relationships, they learn the values, attitudes, techniques, and motives for succeeding as a productive member of society.

\section{LEAD}

Diversion programs are another alternative to incarceration for individuals with drug offenses that can work with or in place of drug court. In King County, Washington, the program LEAD, Law Enforcement Assisted Diversion, was formally implemented in October of 2011. LEAD is a harm reduction pre-booking diversion program. Harm reduction programs focus on taking away potentially harmful objects such as drugs or drug paraphernalia while also referring users to different treatment options instead of an arrest. By not arresting users, LEAD starts to decriminalize addiction and treats the addiction as a disease. Since the diversion with LEAD occurs before an individual is booked, it abolishes the costs that are associated with booking, charging, and court appearances. The idea of LEAD was inspired by an "arrest-referral" policy implemented in the United Kingdom. The arrest referral program refers to the process where an individual is arrested and informed that a drugs worker, their term for a referral or diversion officer, is ready and prepared to take them on, if they would like. If the arrested individual agrees, they are assessed and, if necessary, they are referred to places of treatment. ${ }^{32}$ The success the program saw in the United Kingdom inspired King County to implement a similar policy. The arrest-referral program illustrates how a new policy implemented on a local level can then go on to change the policy of the nation, and eventually lead to policies that countries all over the world implement.

There are three factors that make LEAD unique in comparison to other drug programs and opioid epidemic solutions. Unlike other drug programs, LEAD is the result of the commitment from law enforcement agencies along with community organization and public officials to implement a new approach to drug use seen within the community. The diversion takes place at the pre-booking stage. This differs from other programs, as diversion is often offered after an individual has already been booked and charged. Lastly, LEAD is unique because it not only gives users immediate information on how to get treatment, but also provides individuals with "immediate case management services, and access to additional resources not available through existing public programs". ${ }^{33}$ Since LEAD has only been implemented for eight years, the effects of the program are being continuously analyzed. LEAD measures its effectiveness and successes based on the programs' results in a reduction of drug use and recidivism, if LEAD is more cost-effective than traditional or other alternative criminal justice processing, and if LEAD had a positive impact on the surrounding community's quality of life. ${ }^{33}$ The findings from the first few years of LEAD compares participants in any given month subsequent to their LEAD referral in relation to the month prior to their LEAD referral.

The results show that participants were twice as likely to be sheltered (permanent, temporary, or emergency) compared to being unsheltered during their follow-up. Then, each contact participants had with their LEAD case managers transcribed to a $2 \%$ increase in their likelihood of obtaining shelter. ${ }^{34}$ "Participants were $89 \%$ more likely to obtain permanent housing during the follow-up, and each contact they had with their LEAD case manager translated to a $5 \%$ higher likelihood of being housed during follow-up". ${ }^{34}$ In relation to employment, LEAD participants were $46 \%$ more likely to fall somewhere on the employment continuum during their follow-up compared to before their referral. Participants were also 33\% more likely to have income or benefits of some sort at their follow-up compared to before their LEAD referral. ${ }^{34}$ (Table 1) illustrates the differences in housing, employment, and income before and after a LEAD referral.

At baseline, $82 \%$ of participants were homeless, meaning both unsheltered and unhoused. Following their lead referral, they were "twice as likely to have been sheltered, and were $89 \%$ more likely to have obtained permanent housing after their LEAD referral". ${ }^{34}$ The two categories for housing options were sheltered versus unsheltered and housed versus unhoused. The baseline housing, employment, and income status were based on what participants reported to their case managers when they began the LEAD program. Homelessness was defined using the federal definition including "lacking a fixed, regular and adequate nighttime residence; having a primary nighttime dwelling that is not a regular sleeping accommodation; living in a supervised shelter or transitional housing". ${ }^{34}$ The categories "housed" referred to having permanent housing while "sheltered," referring to any housing, including permanent, temporary, emergency shelter, or a hotel. In both categories, these housing options were in comparison to being homeless for LEAD participants in their 18-month follow-up. ${ }^{34}$ 
Table I Unadjusted descriptive statistics for primary outcomes.

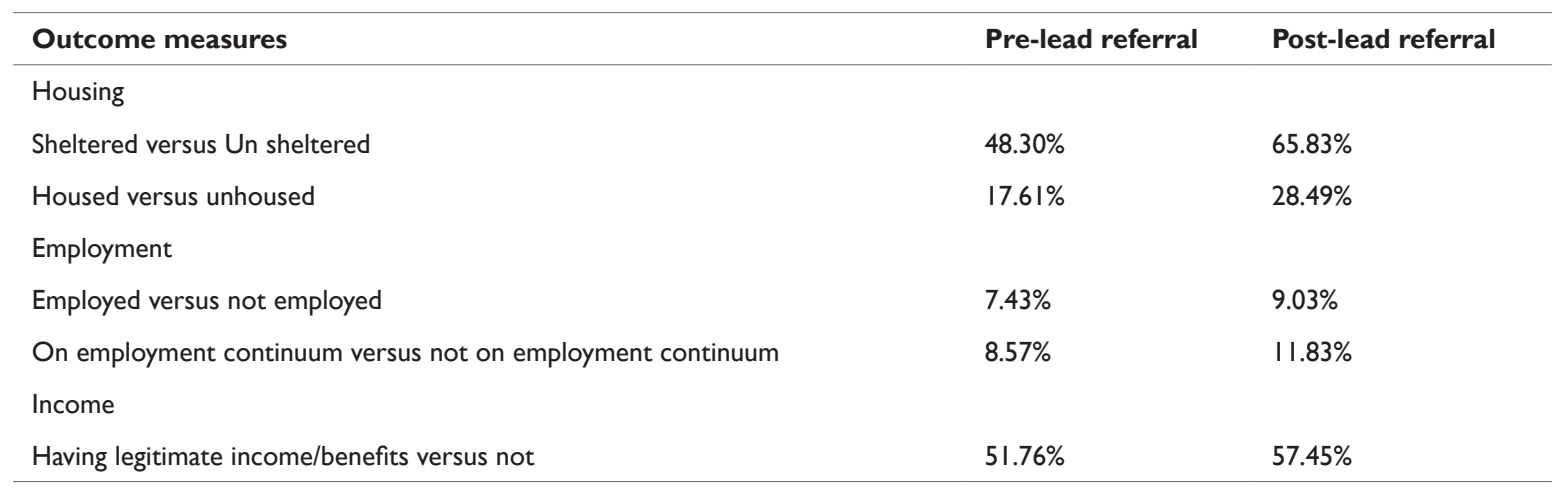

Table I as cited in Clifasefi \& Collins, 2016:II.

Note:This table features unadjusted values. Postreferral values are comprised of the percentage of individuals fitting that category averaged over each month of the 189-8-month follow-up period.

Housing, employment, and income have all been known to lead to less recidivism. Therefore, LEAD can be associated with less recidivism within the drug community as well as King County as a whole. ${ }^{34}$ LEAD participants had $58 \%$ lower chances of at least one arrest, and 39\% lower chances of being arrested for a felony. ${ }^{33}$ While LEAD has seen successful results when analyzing their current findings, there are limitations with the results. Similar to the start of any program, it is hard to form sound conclusions with only a few years of results. Another limitation with the current findings is that LEAD did not have housing, employment, or income data for a control group. In fact, there was no control group that the LEAD participants were compared to. This is because since the majority of LEAD participants were homeless, the findings from this community could not be generalized for communities where their existing programs are different. As a result, the positive correlation between being a LEAD participant and gaining housing, employment, and other benefits could be caused by other outside factors. The lack of the information about the control groups makes the current findings unable to be assumed certain to be a cause and effect relationship. While there were limitations in the current findings, "the fact that increased contact with LEAD case managers predicted better housing outcomes increases [our] confidence that those effects may be attributable to LEAD". ${ }^{34}$

LEAD, as well as other diversion programs, relates to labeling theory through avoiding labeling drug users as criminals. The program provides individuals with access to treatment instead of arresting the users and sending them to prison. Through breaking this cycle of labeling drug users as criminals, LEAD helps to redirect drug offenders by providing them with resources and access to communitybased services and offering a safe environment for these individuals to start recovering and living a more productive life. Along with a safe environment, LEAD also provides a positive support group comprised of law enforcement agencies, public officials, and community groups. Through the formation of strong and meaningful relationships with the members of their support group, the positive results of differential association are highlighted. Compared to the negative consequences that differential association can have on drug users, LEAD fosters a community that works together to help users overcome their addictions long-term. ${ }^{35}$

\section{National policy}

While counties like King County are implementing new programs in hopes of combating their own opioid epidemic, the United States' government is also introducing nationwide policies. The United States Department of Health and Human Services (HHS) established a fivepoint strategy to reduce opioid overdose deaths as well as opioid misuse in general. The five points include better addiction prevention, treatment and recovery services, better data, better pain management (in relation to having pain medication that treats the same intensity of pain without the addictive side effects), better targeting of overdose reversing drugs, and better research. HHS' first and most important point is creating better prevention, treatment, and recovery services for addiction. "In 2017, HHS issued over $\$ 800$ million in grants to support access to opioid-related treatment, prevention, and recovery, while making it easier for states to receive waivers to cover treatment through their Medicaid programs". ${ }^{23}$ HHS also awarded the onebillion-dollar Opioid State Targeted Response (STR) grant funding allocation to the state to solve the opioid problem in their communities. "In September 2017, HRSA awarded \$200 million to health centers nationwide to tackle mental health and fight the opioid overdose crisis including nearly $\$ 4.2$ million in grants to 34 rural health organizations to increase access to treatment and recovery services for opioid abuse in rural communities". ${ }^{23}$

HHS' four other points focus on diversion from opioids. There is a need for better data and research on the effects of opioids. Along with this, there is a need for better research and data on alternatives for pain relief. "Through the NIH HEAL (Helping to End Addiction Longterm) Initiative, NIH supports the development of new, effective, and non-addictive approaches to prevent opioid misuse through enhanced pain management". ${ }^{23}$ HHS' last remaining point focuses on the better availability of overdose-reversing drugs. This point in their plan takes away the focus of preventing opioid overdoses, but rather helps lower the number of deaths related to opioid overdose. While all other points talk about how the nation will hopefully end the opioid epidemic, this point acknowledges that overdoses will still happen, thus preventing people from dying from their overdose is the best short-term solution. "In April 2018, the Surgeon General released an Advisory on Naloxone and Opioid Overdose that emphasized the importance of access to naloxone". ${ }^{23}$ That same month, SAMHSA announced up to $\$ 4.7$ million to Improving Access to Overdose Treatment grants. ${ }^{23}$

When the United States Department of Health and Human Services explained their five-point strategy to combat the nationwide opioid epidemic, they did not include data on findings from their strategy. Their website describes in detail all the money HHS as well as other 
departments have allocated to the cause. Often times the government would allocate a portion of money to each state and have them implement their own strategy. The HHS did not provide data on the feedback from these investments, not showing a relationship between the money being allocated and the opioid overdose death rates. Since there were no data on the outcomes of the programs where money was invested, no real causation can be drawn between HHS' grants and opioid overdose death rates. The programs implemented reflect the values and interests for individual regions. Areas that enforce arrest referral or diversion programs value treatment and rehabilitation for drug users. These programs address the addiction as a sickness and help the user receive the necessary treatment to combat the illness. Local programs like LEAD directly impact their local community and illustrate values of rehabilitation versus punishment. Instead of these communities arresting their opioid users, they focus on providing them with access to treatment.

Nationally, there is a trend to blame individuals for their drug addiction. There is an assumption with drug addicts that they can choose to quit using whenever they wish, ignoring the serious symptoms of drug withdrawal and the severity of opioid addiction. This has led to a medicalized model for solving opioid addiction. The national approach from HHS focuses on an alternative medicalized solution to the opioid epidemic. The HHS is focused on finding an alternative to opioids, in other forms of medication, whether a new less-addictive opioid or a new form of pain pills. The revolving door between the FDA and Big Pharma companies proves the United States values money over ending the opioid epidemic. While the Government talks about combating the opioid epidemic, they continue to approve new addictive opioids. On November 2, 2018 the FDA approved a new opioid, Dsuvia, a drug even more powerful than Fentanyl and that can be administered under the tongue. ${ }^{36}$ Through the policies implemented in relation to the opioid epidemic, the national government has proved they value money.

Recently there has been a national shift in favor of the decriminalization of drugs. Many states have chosen to legalize marijuana within their borders, even though it is still federally illegal. The success of this decriminalization model on the local level allowed for states to adapt the same technique in relation to opioids. Along with the opioid epidemic, the United States is also currently experiencing a mass incarceration epidemic. The decriminalization of drugs like marijuana and street opioids in certain regions has lead to a significant decrease in incarceration rates. The decriminalization of these drugs further proves that there has been a shift in the nation's values from punishing drug users and maintaining a "war on drugs" mentality, to rehabilitating drug users and providing them with the resources to get healthy.

\section{Conclusion of policy recommendations \\ Effects of failed policies}

Past implemented policies have caused unintended consequences in trying to combat drug addiction. For example, the minimum sentencing requirement unintentionally forces the label of deviant and criminal on a drug-offender. This harsh label is what many modern policies are trying to remove and avoid applying to drug users in the future. With a minimum prison sentence, drug users are not only given this label, but also enter a system where that label is reinforced upon them daily. The results showed that mandatory minimum sentences had little or no impact on the spread of drugs throughout the country. The results of this policy further demonstrated the negative consequences of prioritizing labeling drug addicts as criminals instead of as sick individuals in need of support and treatment. The impact of labeling theory is particularly evident here.

\section{Re-stigmatization}

Nationwide, there should be a campaign launched educating the public on the truly addictive qualities of prescription opioids. Before the opioid epidemic began, opioids were heavily labeled as deviant. This was because heroin was the most well known opioid and it carried a significant stigmatization. Prescription opioids lost their stigmatization when they became associated with the healthcare industry. Patients equate trust and safety with their doctors, meaning that they may be blind to the potential risks that lead to addiction. Since opioids like OxyContin were marketed as not having the same addictive properties as other pain killers that is the reputation that the general public still associates with the drug. A nationwide campaign would then be able to re-educate the public on the true dangerous and addictive side effects of prescription opioid painkillers. This campaign would re-stigmatize all opioids to the same level as heroin. This would be a continuation of labeling theory, where all opioids receive the same label as deviant, addictive and dangerous.

\section{Continuing harm reduction}

The United Kingdom started with a few regions switching to a harm reduction approach to tackling their own drug problem, and after significant success, eventually had their entire nation switch to this method. In the United States, programs are being adopted based on this model in different counties. LEAD is an example of one of these programs, and like the programs in the UK, it has seen potentially successful results in the lives of its participants. The success seen on the local level with LEAD reflects the same results as in United Kingdom, suggesting that if the United States would make the shift nationally in harm reduction, the nation would continue to see the same success rates. LEAD's success does face limitations, since the current results offer only a few years in which to measure outcomes, while lacking sufficient data for a control (comparison) group. But, while there are clear limitations, there is confidence from the researchers that increased contact with LEAD officials will predict better housing opportunities and greater income increases. This policy is also an extension of labeling theory. Since harm reduction models strive to remove the label of "criminal" for drug users, harm reduction models have simultaneously been shown to reduce recidivism rates. Through adopting these policies nationwide and removing this powerful label, the U.S. would likely see a reduction in drug-related crimes and hence, the stigmatization they carry.

\section{Acknowledgments}

None.

\section{Conflicts of interest}

The author declares that there are no conflicts of interest.

\section{References}

1. Ogbonna C. Rethinking USA Drug Policy. Journal of Global Intelligence \& Policy. 2012;5(9):107-125.

2. BOP Statistics: Inmate Offenses. Bureau of Prisons (Federal). 2018.

3. Sutherland EH, Cressey DR. Criminology. Philadelphia: Lippincott. 1930. 
4. Becker Howard Saul. Outsiders: Studies in the Sociology of Deviance. New York: Free Press, an Imprint of Simon \& Schuster, Inc. 1963.

5. White WL. Trick or Treat? A Century of American Responses to Heroin Addiction. In: Musto D, editor. One Hundred Years of Heroin. Auburn House. 2002;131-148.

6. Faloon William. FDA Fueled Opioid Epidemic. LifeExtension.com. 2018

7. Vanzile Jon. The Government-Driven Opioid Epidemic. Life Extension. 2018;24(1):76-81.

8. NIDA. National Institute on Drug Abuse. Opioids. NIDA. 2017.

9. NPR. Why Is The Opioid Epidemic Overwhelmingly White? NPR. 2017.

10. Crossman Ashley. An Overview of Labeling Theory. ThoughtCo. 2018.

11. Villa Lauren. Shaming the Sick: Addiction and Stigma. DrugAbuse.com. 2016.

12. What Is Harm Reduction? Harm Reduction Australia. 2018.

13. Downs William R, Joan F Robertson. Control Theory, Labeling Theory, and the Delivery of Services for Drug Abuse to Adolescents. Adolescence, 1997;32(125):1-24.

14. Substance Abuse and Mental Health Services Administration (SAMHSA) Results from the 2016 National Survey on Drug Use and Health (NSDUH): Summary of National Findings. 2016.

15. Carson E. Prisoners in 2013. Bureau of Justice Statistics. Office of Justice Program, U.S. Department of Justice. 2014

16. Glaze LE, Herberman EJ. Correctional Populations in the United States. Bureau of justice statistics. 2013.

17. Incarceration Nation. American Psychological Association. 2014.

18. Myers L. Cultural Divide Over Crime and Punishment. In: Eitzen DS, Leedham CS, editors. Solutions to Social Problems: Lessons from Other Societies 2nd ed. 2001.

19. NIJ. Drugs and Crime Research: Arrestee Drug Abuse Monitoring Programs. National Institute of Justice. 2014.

20. Taxy Sam, Julie Samuels, William Adams. Drug Offenders in Federal Prison: Estimates of Characteristics Based on Linked Data. Bureau of Justice Statistics, U.S Department of Justice. 2012.

21. United States of America, Plaintiff-Appellee, v. Cornelius Demorris BLEWETT (12-5226) and Jarreous Jamone Blewitt (12-5582), Defendants-Appellants. Nos. 12-5226, 12-5582. United States Court of Appeals, Sixth Circuit. 2013.

22. Kolodny. The prescription opioid and heroin crisis: A Public Health Approach to an Epidemic of Addiction. Annual Review of Public Health. 2015;36:559-74.
23. HHS. Opioid Crisis Statistics. U.S department of Health and human services. 2018.

24. Cicero TJ, Ellis MS, Surratt HL. The Changing Face of Heroin Use in the United States. A Retrospective Analysis of the Past 50 Years. JAMA Psychiatry. 2014;71(7):821-826.

25. Mars Sarah G, Philippe Bourgois, George Karandinos, et al. Every 'never' I ever said came true: transitions from opioid pills to heroin injecting. International Journal on Drug Policy. 2013;25(2):257-266.

26. CDC. Public Health Law: Doctor Shopping Laws. Center for Disease Control and Prevention, Office for State, Tribal, Local, and Territorial Support. 2012.

27. Hunt Dana E. Methamphetamine Abuse: Challenges for Law Enforcement and Communities. National Institute of justice. 2006.

28. American Addiction Centers. Using Heroin and Meth Together: Dangers, Treatment, and Effects on Brain and Body. 2018.

29. Volkow ND. Substance Abuse and the Affordable Care Act. Office of National Drug Control Policy (ONDCP). 2007.

30. Lassiter MD. Impossible Criminals: The Suburban Imperatives of America's War on Drugs. The Journal of American history. 2015;102(1):126-140.

31. Lowenkamp CT, Holsinger AM, Latessa EJ. Are drug courts effective? A meta-analytic review. Journal of Community Corrections. 2005; 15(1):5-11.

32. Mair George. Arrest Referral Schemes: First Port of Call for Drug Users in the Criminal Justice Process. Crime and Justice. The Centre for Crime and Justice Studies. 2002;47:16-17.

33. Collins Susan E, Heather S Lonczak, Seema L Clifasefi. LEAD Program Evaluation: Recidivism Report. LEAD, Harm Reduction Research and Treatment Lab University of Washington-Harborview Medical Center. 2015

34. Clifasefi Seema L, Susan E Collins. Lead Program Evaluation: The Impact of LEAD on Housing, Employment and Income/ Benefits. LEAD, Harm Reduction Research and Treatment Center University of WashingtonHarborview Medical Center. 2016.

35. FDA. Statement from FDA Commissioner Scott Gottlieb, M.D., on Agency's Approval of Dsuvia and the FDA's Future Consideration of New Opioids. U S Food and Drug Administration Home Page, Center for Drug Evaluation and Research. 2018.

36. LEAD. Latest News. Law Enforcement Assisted Diversion (LEAD). 2015. 